\title{
Role of HbAlc at Admission on Severity and Functional Outcome of Ischemic Stroke in Patients with Diabetes Mellitus
}

\author{
Sunanda $\mathrm{T}^{1}$, Natuva Sai Sampath Kumar ${ }^{*}$, Amaresh Reddy $\mathrm{P}^{1}$, Ganesh Vallampalli ${ }^{2}$ and Prasad PNS ${ }^{2}$ \\ ${ }^{1}$ Department of Endocrinology, Narayana Medical College and Hospitals, Nellore, AP-524002, India \\ ${ }^{2}$ Department of Neurology, Narayana Medical College and Hospitals, Nellore, AP-524002, India
}

"Corresponding author: Natuva Sai Sampath Kumar, Department of Neurology, Narayana Medical College and Hospital, Chinthareddypalem, Nellore, AP-524002, India, Tel: +91-0861-2317963; E-mail: drnssampath123@gmail.com

Received date: May 14, 2016; Accepted date: June 06, 2016; Published date: June 13, 2016

Copyright: ( 2016 Sunanda T, et al. This is an open-access article distributed under the terms of the Creative Commons Attribution License, which permits unrestricted use, distribution, and reproduction in any medium, provided the original author and source are credited.

\begin{abstract}
Background: Diabetes mellitus the metabolic disorder can interact with atherosclerosis in ischemic strokes to initiate activate and propagate vascular events. To formulate effective preventive measures, it is mandatory to understand the impact of the glycemic status on the severity and functional outcome of Acute Ischemic stroke in patients with diabetes.
\end{abstract}

Purpose of the study: Study the effect of Glycemic status at admission on severity and outcome of Acute Ischemic stroke in patients with diabetes.

Materials and methods: The study is a prospective, case-control, hospital based study done at Department of Neurology, Narayana medical college for a period of $1 \frac{1}{2}$ year.

Results: 130 acute ischemic stroke patients were studied. 100 patients were cases with diabetes mellitus. Remaining 30 patients were controls without diabetes. Case were subcategorised to good glycemic control $(\mathrm{HbA} 1 \mathrm{c}<7)$ and poor glycemic control $(\mathrm{HbA} 1 \mathrm{c}>7)$ 97.5\% patients of poor glycemic control group has moderate to severe stroke severity $>7$ (NIHSS) at admission and $53.3 \%$ of good glycemic control patients has mild severity (NIHSS=1-6). 95\% of good glycemic control group and $96.7 \%$ of non-diabetic control group patients have functional independence at 3 months of follow up. $47.5 \%$ of Poor glycemic control patients have functional dependence at 3 months of follow up.

Conclusion: Glycemic control has significant association on severity and outcome of ischemic stroke patients with diabetes. Estimation of $\mathrm{HbA} 1 \mathrm{c}$ levels at the time of admission might be a predictor of the severity of neurological impairment and functional outcome in patients with acute ischemic stroke and diabetes mellitus.

Keywords: HbA1c; Severity; Outcome; Ischemic stroke; Diabetes

\section{Introduction}

Stroke is the most common clinical manifestation of cerebrovascular disease which represents one of the clinical endpoint of atherosclerosis. It is the disease of the cerebral blood vessels nourishing the brain. World Health Organisation (WHO) defines stroke as an event caused by the interruption of the blood supply to the brain, usually because a blood vessel bursts or is blocked by a clot. Stroke is a global health problem. It is the second commonest cause of death and fourth leading cause of disability worldwide [1].

In most of the ischemic strokes the underlying pathophysiology is atherosclerosis, which is a chronic inflammatory disorder in which immune mechanisms interact with modifiable metabolic risk factor like diabetes mellitus to initiate, activate and propagate vascular events. Diabetes mellitus is a very common metabolic disorder with high and increasing prevalence worldwide.

Risk factors for macrovascular disease in diabetic individuals include dyslipidemia, hypertension, obesity, reduced physical activity, and cigarette smoking. Additional risk factors more prevalent in the diabetic population include microalbuminuria, an elevation of serum creatinine, and abnormal platelet function. Glycemic status is an important variable that can affect the severity and outcome of stroke in patients with diabetes mellitus.

Few studies in literature had revealed the importance of fasting blood glucose [2-6], fasting insulin levels and HbAlc levels on the stroke severity and outcome. In our present study we compared the glycemic status and other risk factors in relation to stroke severity and the functional outcome after a period of 3 months in southern Indian diabetic and non-diabetic population.

\section{Aims and Objectives}

To know the glycemic status by estimating the HbAlc, Fasting and Postprandial plasma glucose at admission among patients with acute ischemic stroke. To study the effect of HBAlc on the severity of stroke at admission and functional outcome at the end of 3 months in acute ischemic stroke patients with diabetes and without diabetes. To compare the poor and good glycemic status patients among the diabetics for the competence of glycemic status on the severity and functional outcome of stroke. 
Citation: Sunanda T, Kumar NSS, Reddy PA, Vallampalli G, Prasad PNS (2016) Role of HbA1c at Admission on Severity and Functional Outcome of Ischemic Stroke in Patients with Diabetes Mellitus. J Neurol Neurophysiol 7: 377. doi:10.4172/2155-9562.1000377

Page 2 of 7

The efficacy of glycemic status especially HBAlc in predicting the severity and functional outcome of acute ischemic stroke can be further empahsised, by comparing it among the poor and good glycemic diabetics with the non-diabetic group patients

\section{Materials and Methods}

The present study was done at department of neurology, Narayana medical college, Nellore for a period of 1 and $1 / 2$ year from January 2014 to June 2015. The current study was a prospective case-control, hospital based study and was approved by the institute ethical committee of Narayana medical college and hospital. The study was done on the patients of Endocrinology, Neurology OPDs and Emergency departments.

A total of 100 acute ischemic stroke patients with diabetes as cases. Cases (All acute ischemic stroke patients with diabetics) were categorised into 2 sub-groups based $\mathrm{HbAlc}$ level at the time of admission as acute ischemic stroke patients with diabetes with good glycemic control (<7 HbAlc) and acute ischemic stroke patients with diabetes with poor glycemic control ( $>7 \mathrm{HbA1c}) .30$ acute Ischemic stroke patients without diabetes as controls. Patients were included in the study after a detailed informed consent.

\section{Inclusion criteria}

- Acute Ischemic stroke patients

\section{Exclusion criteria}

- Intra cerebral haemorrhage
- Space occupying lesions

- Sub arachnoid haemorrhage

- Cerebral venous thrombosis

- Transient ischemic attacks

- Patients with recurrent cerebrovascular events

A Proforma was prepared which includes detailed history, clinical examination and requisite investigations available at Narayana hospital. History includes all of the symptoms pertaining to the ischemic stroke in detail with emphasis on all the risk factors including the glycemic status at the time of admission.

Glycemic status in acute ischemic stroke patients with diabetes was evaluated by measuring the $\mathrm{HbAlc}$ level and fasting and post prandial plasma glucose levels. The stroke severity at admission was assessed based on NIHSS and patients were followed up to discharge and 3 months subsequently. The stroke functional outcome at 3 months was assessed by mRS.

\section{Statistical Analysis}

The data values have been entered into MS-Excel and statistical analysis had been done by using IBM SPSS Version 20.0. For categorical variables the values were represented as number and percentages. To test association between the groups, chi-square test had been used. For continuous variables, the values were represented as mean and standard deviation. To test the mean difference between three or more groups, ANOVA (Analysis of Variance) test with post hoc (Tukey's) test had been used. All the p values were having less than 0.05 were considered as statistically significant.

\begin{tabular}{|c|c|c|c|c|c|c|c|c|}
\hline \multicolumn{9}{|c|}{ CATEGORICAL VARIABLES } \\
\hline S No. & & Variable & GGC N (\%) & PGC N (\%) & Non-Diabetic N (\%) & Total N (\%) & Chi-Square & P-Value \\
\hline \multirow{2}{*}{1} & \multirow{2}{*}{ Sex } & $\mathrm{F}$ & $20(33.3)$ & $8(20.0)$ & $8(26.7)$ & $36(27.7)$ & \multirow{2}{*}{2.151} & \multirow{2}{*}{0.341} \\
\hline & & M & $40(66.7)$ & $32(80.0)$ & $22(73.3)$ & $94(72.3)$ & & \\
\hline \multirow{2}{*}{2} & \multirow{2}{*}{ Smoking } & No & $42(70)$ & $16(40)$ & $20(66.7)$ & $78(60)$ & \multirow{2}{*}{9.722} & \multirow{2}{*}{${ }^{*} 0.008$} \\
\hline & & Yes & $18(30)$ & $24(60)$ & $10(33.3)$ & $52(40)$ & & \\
\hline \multirow{2}{*}{3} & \multirow{2}{*}{ Alcohol } & No & $48(80)$ & $21(52.5)$ & $20(66.7)$ & $89(68.5)$ & \multirow{2}{*}{8.464} & \multirow{2}{*}{${ }^{*} 0.015$} \\
\hline & & Yes & $12(20)$ & $19(47.5)$ & $10(33.3)$ & $41(31.5)$ & & \\
\hline \multirow{2}{*}{4} & \multirow{2}{*}{ HTN } & No & $23(38.3)$ & $9(22.5)$ & $14(46.7)$ & $46(35.4)$ & \multirow{2}{*}{4.803} & \multirow{2}{*}{0.091} \\
\hline & & Yes & $37(61.7)$ & $31(77.5)$ & $16(53.3)$ & $84(64.6)$ & & \\
\hline \multirow{2}{*}{5} & \multirow{2}{*}{$\begin{array}{l}\text { Carotid/Vertebral } \\
\text { Doppler }\end{array}$} & No & $55(91.7)$ & $29(72.5)$ & $30(100)$ & $114(87.7)$ & \multirow{2}{*}{13.643} & \multirow{2}{*}{${ }^{*} 0.001$} \\
\hline & & Yes & $5(8.3)$ & $11(27.5)$ & $0(0)$ & $16(12.3)$ & & \\
\hline \multirow{2}{*}{6} & \multirow{2}{*}{ Toast } & Cardio Embolic & $2(3.3)$ & $1(2.5)$ & $0(0)$ & $3(2.3)$ & \multirow{2}{*}{0.995} & \multirow{2}{*}{0.608} \\
\hline & & Large Artery & $58(96.7)$ & $39(97.5)$ & $30(100)$ & $127(97.7)$ & & \\
\hline
\end{tabular}

Table 1: Baseline descriptive statistics for good glycemic control (GGC), poor glycemic control (PGC) and control group (non-diabetics) [TOAST: Trial of ORG 10172 in Acute Stroke Treatment; HTN: Hypertension]. 


\section{Results}

Total number of patients analysed for the study: 130 , cases were 100 acute ischemic stroke patients with diabetes. They were grouped into good glycemic control $<7 \mathrm{HbA1c}(\mathrm{No}=60)$, poor glycemic control $>$ HbAlc $(\mathrm{No}=40)$. Controls were 30, (acute ischemic stroke patients without Diabetes).

Males were predominant (94/130) comprising $72.3 \%$ of study population. Mean age of patients was $56.78 \pm 12.925$ years. Nonsmokers $(60 \%)$ were more when compared to smokers (40\%). Most of the patients were non-alcoholics (68.5\%). Hypertension was noted in $64.6 \%$ of patients (Table 1 ).

Significant hemodynamic changes $(>50 \%$ stenosis and flow dynamics) were noted in 16 patients $(12.3 \%)$ out of 130 acute ischemic stroke patients. Out of 16,11 patients were poor glycemic control group and 5 from good glycemic control. None of the non-diabetic patients had significant doppler findings. Based on TOAST classification for etiology, 127 patients had large artery to artery atherosclerotic etiology, whereas, 3 patients had cardio-embolic etiology.
For the patients distribution among these sub groups age, smoking, alcoholism had significant correlation $(\mathrm{p}<0.05)$. Sex and hypertension did not have positive correlation among patients of 3 groups. Significant hemodynamic abnormalities on carotid/vertebral doppler were mostly noted in poor glycemic control patients when compared to good glycemic control and non-diabetic subgroup patients with $\mathrm{P}=0.001$. TOAST classification for etiology had no significant statistical distribution among 3 groups of patients. $60 \%$ of patients of poor glycemic control were smokers whereas nearly $65 \%$ of patients of good glycemic control and non-diabetic group were non-smokers. Similarly majority of alcoholic patients were from poor glycemic control group.

Patients of poor glycemic control had high total cholesterol, VLDL, TGL values when compared to good glycemic control and nondiabetic groups $(\mathrm{P}<0.05)$ (Table 2$)$ Despite high mean LDL values noted in poor glycemic control patients, it had no statistically significant correlation. High mean HDL values were noted in good glycemic control patients and it had no statistical correlation among three groups. TGL/HDL had also statistical significance (0.003) distribution among 3 groups.

\begin{tabular}{|c|c|c|c|c|c|c|c|}
\hline \multicolumn{8}{|c|}{ CONTINUOUS VARIABLES } \\
\hline \multirow{2}{*}{ S No. } & \multirow{2}{*}{ VARIABLE } & GGC & PGC & NON-DIABETIC & TOTAL & \multirow{2}{*}{ F-VALUE } & \multirow{2}{*}{ P-VALUE } \\
\hline & & NO:60 & NO:40 & NO:30 & 130 & & \\
\hline 1 & AGE & $53.53 \pm 11.864$ & $59.95 \pm 12.397$ & $59.03 \pm 14.459$ & $56.78 \pm 12.925$ & 3.7 & * 0.027 \\
\hline 2 & TOTAL (CHOL) & $186.78 \pm 39.266$ & $207.63 \pm 47.669$ & $173.23 \pm 48.680$ & $190.07 \pm 45.732$ & 5.493 & ${ }^{*} 0.005$ \\
\hline 3 & $\mathrm{HDL}$ & $46.02 \pm 11.425$ & $45.35 \pm 14.677$ & $44.67 \pm 13.311$ & $45.5 \pm 12.843$ & 0.133 & 0.893 \\
\hline 4 & LDL & $104.15 \pm 31.418$ & $113.08 \pm 42.340$ & $102.87 \pm 34.859$ & $106.6 \pm 35.856$ & 0.954 & 0.388 \\
\hline 5 & VLDL & $30.40 \pm 14.141$ & $42.6 \pm 20.808$ & $22.03 \pm 8.888$ & $32.22 \pm 17.297$ & 15.625 & ${ }^{*}<0.0001$ \\
\hline 6 & TGL & $141.12 \pm 55.986$ & $181.50 \pm 76.827$ & $112.73 \pm 44.058$ & $146.99 \pm 65.671$ & 11.438 & $*<0.0001$ \\
\hline 7 & TGL/HDL & $3.2922 \pm 1.68654$ & $4.8901 \pm 4.52607$ & $2.6880 \pm 1.07635$ & $3.6444 \pm 2.91654$ & 6.154 & ${ }^{*} 0.003$ \\
\hline 8 & FPG & $103.80 \pm 24.534$ & $161.28 \pm 55.449$ & $97 \pm 22.148$ & $119.92 \pm 45.7$ & 37.34 & $*<0.0001$ \\
\hline 9 & PPG & $133.47 \pm 37.989$ & $209.53 \pm 65.216$ & $120.33 \pm 27.977$ & $153.84 \pm 59.477$ & 42.366 & $*<0.0001$ \\
\hline 10 & $\mathrm{HbA1C}(\mathrm{ADM})$ & $5.9217 \pm 0.46106$ & $8.5050 \pm 1.26003$ & $5.74 \pm 0.40224$ & $6.6746 \pm 1.45577$ & 155.823 & ${ }^{*}<0.0001$ \\
\hline 11 & TSH & $5.4572 \pm 4.031718$ & $4.6955 \pm 2.41902$ & $2.2783 \pm 1.23521$ & $4.4892 \pm 3.49602$ & 9.467 & ${ }^{*}<0.0001$ \\
\hline 12 & NIHSS(ADM) & $6.47 \pm 2.213$ & $12.3 \pm 3.180$ & $8.73 \pm 4.315$ & $8.78 \pm 3.977$ & 42.401 & ${ }^{*}<0.0001$ \\
\hline 13 & $\mathrm{mRS}(3 \mathrm{M})$ & $1.15 \pm 0.732$ & $2.23 \pm 1.050$ & $1.53 \pm 0.730$ & $1.57 \pm 0.956$ & 19.584 & $*<0.0001$ \\
\hline
\end{tabular}

Table 2: Baseline descriptive statistics for good glycemic control (GGC), poor glycemic control (PGC) and control group (non-diabetics). [Chol: Cholesterol; HDL: High Density Lipoprotein; LDL: Low Density Lipoprotein; VLDL: Very Low Density lipoprotein; TGL: Trigylcerides; FPG: Fasting Plasma Glucose; PPG: Post prandial Plasma Glucose; TSH: Thyroid Stimulating Hormone; NIHSS: National Institute of Health Stroke Score; mRS: modified Rankin Score; HbAlc: Glycated Haemoglobin; ADM: Admission].

Glycemic status indicatiors like FPG, PPG, HbA1C had very high statistical significance (0.0001) values among 3 groups of patients. High mean FPG of $161.28 \mathrm{mg} / \mathrm{dl}$ was noted in poor glycemic control groups when compared to $103.8 \mathrm{mg} / \mathrm{dl}$ in good glycemic control $97 \mathrm{mg}$ $\%$ in non-diabetic group. PPG also had similar trend of statistical distribution among 3 groups with high mean PPG of $209.53 \mathrm{mg} \%$ was noted in poor glycemic group. Poor glycemic control group had statistically significant high $\mathrm{HbAlc}$ value $8.5 \pm 1.26$ when compared to good glycemic control group $(5.92 \pm 0.46)$ and non-diabetics $(5.74 \pm$ $0.4)$.

TSH values were significantly high among diabetic (good and poor glycemic) group compared to control group $(<0.0001)$. 
Citation: Sunanda T, Kumar NSS, Reddy PA, Vallampalli G, Prasad PNS (2016) Role of HbA1c at Admission on Severity and Functional Outcome of Ischemic Stroke in Patients with Diabetes Mellitus. J Neurol Neurophysiol 7: 377. doi:10.4172/2155-9562.1000377

Page 4 of 7

\section{Stroke severity at admission (NIHSS) in cases $v s$. control groups}

97.5\% patients of poor glycemic control group had moderate to severe stroke severity ( $>7$ NIHSS) at admission. Whereas half of patients (53.3\%) of good glycemic control had mild severity (NIHSS=1-6) (Table 3).

\begin{tabular}{|c|c|c|c|c|c|c|c|c|}
\hline S No. & NIHSS & Variable & GGC N (\%) & PGC N (\%) & Non-diabetic N (\%) & Total N (\%) & Chi-Square & P-Value \\
\hline \multirow{3}{*}{1} & Mild & 6-Jan & $32(53.3)$ & $1(2.5)$ & $10(33.3)$ & $43(33.1)$ & \multirow{3}{*}{55.259} & \multirow{3}{*}{${ }^{*}<0.0001$} \\
\hline & Moderate & 12-Jul & $27(45)$ & $20(50)$ & $19(63.3)$ & $66(50.8)$ & & \\
\hline & Severe & $>12$ & $1(1.7)$ & $19(47.5)$ & $1(3.3)$ & $21(16.2)$ & & \\
\hline
\end{tabular}

Table 3: Stroke severity at admission (NIHSS) in cases vs. control groups.

Stroke functional outcome at 3 months (mRS) in cases $v s$. control groups

Significant percentage of good glycemic control group (95\%) and non-diabetic control group $(96.7 \%)$ patients had functional independence at 3 months of stroke follow up. Proportionally $47.5 \%$ of poor glycemic control patients had functional dependence at 3 months of stroke follow up. Statistics significantly illustrates glycemic effect on functional outcome of acute ischemic stroke patients at 3 months follow up (Table 4).

\begin{tabular}{|l|l|l|l|l|l|l|l|l|}
\hline S. No & mRS & Variable & GGC N (\%) & PGC N (\%) & Non-diabetic N (\%) & Total N (\%) & Chi-Square & P-Value \\
\hline \multirow{2}{*}{1} & Independent & $0-2$ & $57(95)$ & $21(52.5)$ & $29(96.7)$ & $107(82.3)$ & \multirow{2}{*}{35.291} & $*<0.0001$ \\
\cline { 2 - 8 } & Dependent & $6-M a r$ & $3(5)$ & $19(47.5)$ & $1(3.3)$ & $23(17.7)$ & \\
\hline
\end{tabular}

Table 4: Stroke functional outcome at 3 months (mRS) in cases vs. control groups.

\begin{tabular}{|c|c|c|c|c|}
\hline \multirow{2}{*}{ S. NO } & \multirow{2}{*}{ Variable } & GGC & PGC & \multirow{2}{*}{$P$ value } \\
\hline & & NO: 60 & NO: 40 & \\
\hline 1 & Age & $53.53 \pm 11.864$ & $59.95 \pm 12.397$ & ${ }^{*} 0.038$ \\
\hline 2 & Total (Chol) & $186.78 \pm 39.266$ & $207.63 \pm 47.669$ & 0.058 \\
\hline 3 & $\mathrm{HDL}$ & $46.02 \pm 11.425$ & $45.35 \pm 14.677$ & 0.965 \\
\hline 4 & LDL & $104.15 \pm 31.418$ & $113.08 \pm 42.340$ & 0.444 \\
\hline 5 & VLDL & $30.40 \pm 14.141$ & $42.6 \pm 20.808$ & ${ }^{*} 0.001$ \\
\hline 6 & TGL & $141.12 \pm 55.986$ & $181.50 \pm 76.827$ & *0.004 \\
\hline 7 & TGL/HDL & $3.2922 \pm 1.68654$ & $4.8901 \pm 4.52607$ & * 0.017 \\
\hline 8 & FPG & $103.80 \pm 24.534$ & $161.28 \pm 55.449$ & ${ }^{*}<0.0001$ \\
\hline 9 & PPG & $133.47 \pm 37.989$ & $209.53 \pm 65.216$ & ${ }^{*}<0.0001$ \\
\hline 10 & $\mathrm{HbA1C}$ (ADM) & $5.9217 \pm 0.46106$ & $8.5050 \pm 1.26003$ & ${ }^{*}<0.0001$ \\
\hline 11 & TSH & $5.4572 \pm 4.031718$ & $4.6955 \pm 2.41902$ & 0.494 \\
\hline 12 & NIHSS (ADM) & $6.47 \pm 2.213$ & $12.3 \pm 3.180$ & ${ }^{*}<0.0001$ \\
\hline 13 & mRS (3M) & $1.15 \pm 0.732$ & $2.23 \pm 1.050$ & ${ }^{*}<0.0001$ \\
\hline
\end{tabular}

Table 5: Baseline descriptive statistics for good glycemic control (GGC) and poor glycemic control (PGC) groups.

\section{Good glycemic control vs. poor glycemic control}

Dyslipidemic fractions like VLDL, TGL, TGL/HDL and glycemic indicators like FPG, PPG and HbAlc were having positive statistical correlation between the two groups. Poor glycemic control group had high stroke severity at admission and dependant functional outcome at 3 months when compared to good glycemic control group patients. 
Page 5 of 7

Glycemic control had significant association on severity and outcome of ischemic stroke patients with diabetes (Table 5).

\section{Poor glycemic control vs. non-diabetics}

There were statistically significant correlations noted between the poor glycemic control group and non-diabetic group. Poor glycemic control group had high stroke severity at admission and dependant functional outcome at 3 months when compared to control group patients (Table 6).

\begin{tabular}{|c|c|c|c|c|}
\hline \multirow{2}{*}{ S No. } & \multirow{2}{*}{ Variable } & PGC & Non-Diabetic & \multirow{2}{*}{$p$-value } \\
\hline & & NO:40 & NO:30 & \\
\hline 1 & Age & $59.95 \pm 12.397$ & $59.03 \pm 14.459$ & 0.952 \\
\hline 2 & Total (Chol) & $207.63 \pm 47.669$ & $173.23 \pm 48.680$ & ${ }^{*} 0.005$ \\
\hline 3 & $\mathrm{HDL}$ & $45.35 \pm 14.677$ & $44.67 \pm 13.311$ & 0.974 \\
\hline 4 & LDL & $113.08 \pm 42.340$ & $102.87 \pm 34.859$ & 0.468 \\
\hline 5 & VLDL & $42.6 \pm 20.808$ & $22.03 \pm 8.888$ & ${ }^{*}<0.0001$ \\
\hline 6 & TGL & $181.50 \pm 76.827$ & $112.73 \pm 44.058$ & ${ }^{*}<0.0001$ \\
\hline 7 & TGL/HDL & $4.8901 \pm 4.52607$ & $2.6880 \pm 1.07635$ & ${ }^{*} 0.004$ \\
\hline 8 & FPG & $161.28 \pm 55.449$ & $97 \pm 22.148$ & ${ }^{*}<0.0001$ \\
\hline 9 & PPG & $209.53 \pm 65.216$ & $120.33 \pm 27.977$ & ${ }^{*}<0.0001$ \\
\hline 10 & HbA1C (ADM) & $8.5050 \pm 1.26003$ & $5.74 \pm 0.40224$ & ${ }^{*}<0.0001$ \\
\hline 11 & TSH & $4.6955 \pm 2.41902$ & $2.2783 \pm 1.23521$ & ${ }^{*} 0.008$ \\
\hline 12 & NIHSS (ADM) & $12.3 \pm 3.180$ & $8.73 \pm 4.315$ & ${ }^{*}<0.0001$ \\
\hline 13 & mRS (3M) & $2.23 \pm 1.050$ & $1.53 \pm 0.730$ & ${ }^{*} 0.003$ \\
\hline
\end{tabular}

Table 6: Baseline descriptive statistics for poor glycemic control (PGC) and Non diabetics.

\section{Good glycemic control (GGC) and non-diabetics}

There were no statistical significant associations between the two groups regarding age and dyslipidemic fractions except for VLDL. Similarly glycemic indicators (FPG PPG and HbA1c) were not different between the groups. Interesting finding to be noted was stroke severity and functional outcomes are not different between the ischemic patients of good glycemic control group and non-diabetic group. TSH was significantly higher among diabetic patients compared to non-diabetics but it was not significantly different between good and poor glycemic control groups (Table 7).

\begin{tabular}{|l|l|c|c|c|}
\hline \multirow{2}{*}{ S No. } & \multirow{2}{*}{ Variable } & GGC & Non-Diabetic & \multirow{2}{*}{ p value } \\
\cline { 3 - 5 } & & NO: 60 & NO: 30 & \\
\hline 1 & Age & $53.53 \pm 11.864$ & $59.03 \pm 14.459$ & 0.131 \\
\hline 2 & Total (Chol) & $186.78 \pm 39.266$ & $173.23 \pm 48.680$ & 0.359 \\
\hline 3 & HDL & $46.02 \pm 11.425$ & $44.67 \pm 13.311$ & 0.887 \\
\hline 4 & LDL & $104.15 \pm 31.418$ & $102.87 \pm 34.859$ & 0.986 \\
\hline 5 & VLDL & $30.40 \pm 14.141$ & $22.03 \pm 8.888$ & $* 0.047$ \\
\hline
\end{tabular}

\begin{tabular}{|l|l|c|c|c|}
\hline 6 & TGL & $141.12 \pm 55.986$ & $112.73 \pm 44.058$ & 0.097 \\
\hline 7 & TGL/HDL & $3.2922 \pm 1.68654$ & $2.6880 \pm 1.07635$ & 0.602 \\
\hline 8 & FPG & $103.80 \pm 24.534$ & $97 \pm 22.148$ & 0.684 \\
\hline 9 & PPG & $133.47 \pm 37.989$ & $120.33 \pm 27.977$ & 0.417 \\
\hline 10 & HbA1C (ADM) & $5.9217 \pm 0.46106$ & $5.74 \pm 0.40224$ & 0.56 \\
\hline 11 & TSH & $5.4572 \pm$ & $2.2783 \pm 1.23521$ & $*<0.0001$ \\
\hline 12 & NIHSS(ADM) & $6.47 \pm 2.213$ & $8.73 \pm 4.315$ & 0.064 \\
\hline 13 & mRS(3M) & $1.15 \pm 0.732$ & $1.53 \pm 0.730$ & 0.108 \\
\hline
\end{tabular}

Table 7: Baseline descriptive statistics for good glycemic control (GGC) and non-diabetics.

\section{Discussion}

Ischemic stroke is a heterogeneous pathophysiological state in which varied different pathways might lead to indistinguishable clinical presentations that result in high mortality rates and severe disabilities. Well recognized etiologies of ischemic stroke include cardiac or artery-to-artery embolism and atherothrombosis of an extracranial and intracranial carotid and vertebral artery systems due to Type 2 diabetes mellitus. However, it is generally accepted that atherosclerosis of extracranial or intracranial arteries due to Type 2 diabetes mellitus accounts for a substantial proportion of clinical ischemic strokes.

This is one of few clinical studies where the role of glycemic status is systematically evaluated with respect to stroke severity and functional outcome.

The current study reports a prospective study which includes of 130 patients recruited from emergency and outpatient departments of Neurology who were admitted with acute ischemic stroke. As in other studies $[7,8]$, the current study also showed male predominance. The accumulation of traditional risk factors and along with aging in males is likely to explain the male predominance among acute ischemic stroke patients.

The current study shown that smoking had statistical distribution among all the three groups of patients. Majority of poor glycemic control group patients were smokers when compared to non-diabetic group, similar finding was noted by other studies [9-11]. There is significant evidence that smoking increases the risk of diabetes. Smoking is associated with central obesity. Smoking also increases inflammation and oxidative stress, to directly damage $\beta$-cell function and to impair endothelial function.

Alcohol also had similar association with diabetes among three groups where predominant alcoholics were from poor glycemic control which is consistent with other series reported by some authors [12-14].

Diabetes mellitus is recognized clinically as a complication of alcoholism. Heavy amounts of alcohol show direct diabetogenic effects with its contribution to excess caloric intake and obesity, induction of pancreatitis, disturbance of the carbohydrate and glucose metabolism and the impairment of the liver function, which affects the blood glucose levels. 
TSH was significantly higher among diabetic patients compared non-diabetic but it was not significantly different between good and poor glycemic control groups.

The prevalence of thyroid disorder in diabetic population was reported to be $13.4 \%$ with higher prevalence $(31.4 \%)$ in female type 2 diabetic patients as compared to $(6.9 \%)$ in male type 2 diabetic patients [15]. The prevalence of thyroid dysfunction in type 2 diabetic patients was reported to be $12.3 \%$ in Greece and $16 \%$ in Saudi Arabia by Akbar et al. [16] considerably; type 2 diabetic patients were more prone to thyroid disorders. The prevalence of thyroid disorders was as high as $31 \%$ in a study done from India [17].

The pathophysiological pathway connecting these two disorders has not been clearly delineated as of now. The most obvious connection, perhaps, is the increased BMI and insulin resistance common to both conditions. Obesity, stroke is associated with an altered milieu with increase in proinflammatory markers and increase in insulin resistance. This, through undefined mechanisms, leads to decreased deiodinase 2 activity at pituitary level resulting in relative T3 deficiency and increase in TSH levels [18]. The exact mechanism by which poor glycemic control affects severity and outcome of ischemic stroke patients is less clear. General complications related to poorly controlled glycemic status could be one explanation. An increased HbA1C level reflects poor long term glycemic control and has its specific implications on the structure and function of vascular bed including small as large cerebral vessels. Increased $\mathrm{HbAlc}$ level might also be a marker of poor compliance indicating an unhealthy life style.

Evidence is compelling that increased stroke risk is associated with high levels of total cholesterol and low-density lipoprotein, and decreased high-density lipoprotein levels. In the Helsinki young stroke registry [19], dyslipidemia was clearly the most prominent well documented risk factor. In the present study also results shown that high mean levels of total cholesterol $(<0.005)$ and very low-density lipoprotein $(<0.0001)$, and Triglycerides $(<0.0001)$ levels in patients of ischemic stroke with poor glycemic control when compared with good glycemic control and Non-diabetics ischemic stroke patients [20-22].

Kizer et al. [23] studied the relationship between HbAlc and stroke. The results showed that after adjusting age, gender, smoking, blood lipids and other variances, $\mathrm{HbAlc}$ and stroke risk was significantly associated. They emphasized that strict control of glycated haemoglobin $(\mathrm{HbAlc})$ might be benefit for stroke prevention for the patients with diabetes. The present study showed that FPG, PPG values on admission, NIHSS scores, three months MRS score, when compared among three groups of patients, the difference was statistically significant $(\mathrm{P}<0.0001)$. Patients with high $\mathrm{HbAlc}$, high FPG, high PPG had high NIHSS score at admission with poor outcomes at 3 months $(\mathrm{P}<0.001)$. That is to say, a higher HbAlc level will have a more serious neurological impairment, and the clinical condition might be more serious. So, HbAlc levels at admission might be an important predictor to evaluate the neurological impairment in patients with acute ischemic stroke. In neurological impairment aspect, on admission, serious patients( $>12$ NIHSS) of poor glycemic control accounted for $47.5 \%$, that is higher than good glycemic control $(1.7 \%)$ and non-diabetics (3.3\%).In three months functional outcome aspects, dependent ( $>2$ MRS) patients of poor glycemic control group accounted for $47.5 \%$, that is higher than good glycemic control (5\%), non-diabetic (3.3\%). And a higher HbAlc levels has a more serious neurological impairment on admission and the prognosis is worse after three months. The mechanism might be associated with long-term high blood glucose and high blood HbAlc,which lead to lesions of large blood vessels and which lead to oxygen dissociation curve to the left, resulting in oxygen dissociation barrier, nerve tissue ischemia and hypoxia, that is not benefit for the recovery of neurological function, and the prognosis is worse. This result is in line with the result of Kamouchi et al. [24], who studied 3627 patients, the result showed that neurological improvement is lower relevant to age and sex and is higher relevant to the blood HbAlc level on admission. In summary, the current study suggests that blood HbAlc levels on admission may influence severity in patients with acute ischemic stroke and may adversely predict three months prognosis. So, HbAlc levels maybe is an important predictors to evaluate the neurological impairment and three months prognosis in patients of acute ischemic stroke with diabetes.

Therefore, effectively lowering blood $\mathrm{HbAlc}$ levels may reduce the severity of neurological impairment in patients with acute ischemic stroke, and may be can improve the life quality of patients with acute ischemic stroke.

A novel and very unique finding we derived from out study is that maintaining good glycemic goal is equally effective in reducing stroke severity and improved functional independence at 3 months of follow up when compared with Non-diabetic status. This conclusion is evident by no statistical correlation between the groups with reference to stroke severity $(<0.06)$, stroke functional outcome $(0.108)$.

Limitation of this study is that we did not measure the size of the stroke lesion by CT or MRI, however it is well known that NIHSS score is a good clinical severity measure, which parallels infarct volume. We have not considered diabetic complications and other complications related to other systems during follow up period which will affect the prognosis.

Based on results from this prospective study additional studies are needed to elucidate desired glycemic goal (HbA1C less than 7) for prevention of ischemic stroke and to effectively decrease stroke severity and improve functional outcome of acute ischemic stroke.

Further studies are needed to elucidate whether treatment to provide good glycemic control before onset of stroke improves clinical course and outcome in patients with ischemic stroke.

\section{Conclusion}

By performing the study with non-diabetic controls the current study was able to analyse and identify distinctly the clinical effects of diabetes mellitus on the outcome of acute ischemic stroke. Among the diabetic stroke patients the severity of deranged glycemic status found to have an influencing effect on the stroke severity and functional outcome. Clustering of other risk factors like old age, smoking, alcoholism and dyslipidemia are observed in acute ischemic stroke patients with poor glycemic status. Estimation of HbAlc levels at the time of admission might be a predictor of the severity of neurological impairment and functional outcome in patients with acute ischemic stroke. With achievement of near normal glycemic status in diabetic population the stroke severity and functional outcome levels can be brought to the same extent of that observed in non-diabetic population.

\section{References}

1. Strong K, Mathers C, Bonita R (2007) Preventing stroke: Saving lives around the world. Lancet Neurol 6: 182-187. 
Citation: Sunanda T, Kumar NSS, Reddy PA, Vallampalli G, Prasad PNS (2016) Role of HbA1c at Admission on Severity and Functional Outcome of Ischemic Stroke in Patients with Diabetes Mellitus. J Neurol Neurophysiol 7: 377. doi:10.4172/2155-9562.1000377

Page 7 of 7

2. Hjalmarsson C, Manhem K, Bokemark L, Andersson B (2014) The role of pre-stroke glycemic control on severity and outcome of acute ischemic stroke. Stroke Res Treat 2014: 694569.

3. Lawlor DA, Fraser A, Ebrahim S, Smith GD (2007) Independent associations of fasting insulin, glucose and glycated haemoglobin with stroke and coronary heart disease in older women. PLoS Med 4: e263.

4. Roquer J, Giralt-Steinhauer E, Cerdà G, Rodríguez-Campello A, Cuadrado-Godia E, et al. (2015) Glycated haemoglobin value combined with initial glucose levels for evaluating mortality risk in patients with ischemic stroke. Cerebrovasc Dis 40: 244-250.

5. Murros K, Fogelholm R, Kettunen S, Vuorela AL, Valve J (1992) Blood glucose, glycosylated haemoglobin and outcome of ischemic brain infarction. J Neurol Sci 111: 59-64.

6. Roquer J, Rodríguez-Campello A, Cuadrado-Godia E, Giralt-Steinhauer E, Jiménez-Conde J, et al. (2014) Ischemic stroke in prediabetic patients. J Neurol 261: 1866-1870.

7. Kuwashiro T, Sugimori H, Ago T, Kuroda J, Kamouchi M, et al. (2013) The impact of predisposing factors on long-term outcome after stroke in diabetic patients: the Fukuoka Stroke Registry. Eur J Neurol 20: 921-927.

8. Smith MA, Lisabeth LD, Brown DL, Morgenstern LB (2005) Gender comparisons of diagnostic evaluation for ischemic stroke patients. Neurology 65: 855-858.

9. Chang SA (2012) Smoking and type 2 diabetes mellitus. Diabetes Metab J 36: 399-403.

10. Prasad S, Cucullo L (2015) Impact of tobacco smoking and type-2 diabetes mellitus on public health: A cerebrovascular perspective. J Pharmacovigil Suppl 2.

11. Eliasson B (2003) Cigarette smoking and diabetes. Prog Cardiovasc Dis 45: 405-413.

12. van de Wiel A (2004) Diabetes mellitus and alcohol. Diabetes Metab Res Rev 20: 263-267.

13. Kim SJ, Kim DJ (2012) Alcoholism and diabetes mellitus. Diabetes Metab J 36: 108-115.
14. Wannamethee SG, Shaper AG, Perry IJ, Alberti KG (2002) Alcohol consumption and the incidence of type II diabetes. J Epidemiol Community Health 56: 542-548.

15. Perros P, McCrimmon RJ, Shaw G, Frier BM (1995) Frequency of thyroid dysfunction in diabetic patients: Value of annual screening. Diabet Med 12: 622-627.

16. Akbar DH, Ahmed MM, Al-Mughales J (2006) Thyroid dysfunction and thyroid autoimmunity in Saudi type 2 diabetics. Acta Diabetol 43: 14-18.

17. Demitrost L, Ranabir S (2012) Thyroid dysfunction in type 2 diabetes mellitus: A retrospective study. Indian J Endocrinol Metab 16: S334-335.

18. Muscogiuri G, Sorice GP, Mezza T, Prioletta A, Lassandro AP, et al. (2013) High-normal TSH values in obesity: Is it insulin resistance or adipose tissue's guilt? Obesity (Silver Spring) 21: 101-106.

19. Putaala J, Metso AJ, Metso TM, Konkola N, Kraemer Y, et al. (2009) Analysis of 1008 consecutive patients aged 15 to 49 with first-ever ischemic stroke, The Helsinki Young Stroke Registry. Stroke 40: 1195-1203.

20. Tuomilehto J, Rastenyte D, Jousilahti P, Sarti C, Vartiainen E (1996) Diabetes mellitus as a risk factor for death from stroke. Prospective study of the middle-aged Finnish population. Stroke 27: 210-215.

21. Megherbi SE, Milan C, Minier D, Couvreur G, Osseby GV, et al. (2003) Association between diabetes and stroke subtype on survival and functional outcome 3 months after stroke: Data from the European Biomed Stroke Project. Stroke 34: 688-694.

22. Mankovsky BN, Ziegler D (2004) Stroke in patients with diabetes mellitus. Diabetes Metab Res Rev 20: 268-287.

23. Kizer JR, Wiebers DO, Whisnant JP, Galloway JM, Welty TK, et al. (2006) Glycernic level and future stroke in type 2 diabetes mellitus: The strong heart study. Circulation 114: 444-446.

24. Kamouchi M, Matsuki T, Hata J, Kuwashiro T, Ago T, et al. (2011) Prestroke glycemic control is associated with the functional outcome in acute ischemic stroke: The Fukuoka Stroke Registry. Stroke 42: 2788-2794. 